\title{
Analysis of the Status Quo and Countermeasures of Civil Construction Technology in Building Engineering
}

\author{
Benyu Zhao \\ Chongqing College of Architecture and Technology, 401331
}

\begin{abstract}
The rapid development of the construction industry has made great progress in civil engineering construction technology. As an important part of the construction of civil engineering construction, the advanced nature of its construction technology is directly related to the overall engineering construction level, and affects the construction of other projects in the later period. To this end, we must master the essentials of basic civil construction technology. At the same time, we also need to improve and innovate existing technologies based on market demand, learn the essence of advanced technologies and combine them with engineering practices, and innovate engineering quality management methods. Only in this way can the quality of civil engineering be ensured. In view of this, this article will discuss how to improve the quality of civil engineering through the innovation of ideas, systems and technologies on the basis of analyzing the status quo of the application of civil engineering technology in construction engineering.
\end{abstract}

\section{Significance of Civil Engineering Construction Technology}

Civil construction technology is the most common type of construction engineering, and the quality of civil construction technology is directly related to the quality of construction engineering. In the fierce market competition, if companies want to gain a place, they must strengthen technological innovation and quality control. Only by adopting advanced construction technology and innovative quality management concepts can enterprises improve the quality of projects. In the meantime, this can also reduce the overall cost of the project, increase economic benefits, and lay a solid foundation for the sustainable development of construction projects. In the actual construction of construction projects, the application effect of civil construction technology is related to the actual construction environment, the construction personnel, and the strength of the construction unit. The civil construction technology must be combined with the actual project to give full play to its maximum application value. Otherwise, just completing the project on time may not guarantee the quality of the project. If rework occurs later due to quality problems, it will increase engineering costs. Therefore, construction units and construction personnel must be aware of the impact of civil construction technology on the overall project. Only by mastering the key points of civil construction technology, continuously summing up the experience in practice, discovering and solving problems in time, and appropriately introducing advanced science and technology and equipment, and continuously improving their technical application level, can they ensure the quality of the main structure of the project and reduce quality and safety hazards. This will lay a good foundation for later decoration construction and electrical installation construction.

\section{The Status Quo of Civil Construction Technology in Building Engineering}

\subsection{Research and Development Status}

With the rapid development of science and technology and the in-depth research on construction technology of construction projects, many new materials and new technologies have appeared in the construction market. The emergence and application of these new materials and new technologies are of great significance for improving the overall level of civil engineering construction, including construction quality and construction efficiency. However, in actual construction projects, whether the technology used by the construction unit is advanced and scientific is mainly related to the strength of the unit, the needs of the construction unit, the scale of the project, and the difficulty of construction, as well as related systems, funds, and personnel. Some units have a poor sense of innovation, coupled with their own internal management system is not perfect, financial strength is poor, and the staff team is uneven. This has led to enterprises not being able to truly play the role of 
civil construction technology, making the application of technology less effective and unable to achieve better engineering benefits. In terms of research on construction technology of construction projects, the theoretical research at this stage has made good progress, and has also begun to strengthen the research on new technologies, especially automation and intelligent technologies. But as a whole, there is a derailment between theoretical research and practical application, and theory cannot really guide practice. As a result, people pay less attention to the application of some new technologies. Many companies lack innovative talents, and the training intensity has not kept up, resulting in insufficient innovation capabilities of the entire enterprise, which will also affect the innovation and development of technology [1].

\subsection{Application Status and Existing Problems}

There are two common problems in civil engineering construction technology. First, the security is not strong enough. Although many new technologies and equipment have emerged, and intelligent and automated construction methods have also been adopted, more and more complex building structures have also emerged at the same time. These building structures have very high requirements for construction technology. Once there are some loopholes in the construction technology, the entire construction may be paralyzed, bringing great safety hazards to the project. In consequence, we must take safe construction as a prerequisite while improving construction technology. We should carry out engineering design based on the characteristics of specific civil engineering, and choose scientific and reasonable construction technology according to the design plan. Especially in the construction of the foundation part of a building project, we must ensure that the structure has sufficient strength and supporting capacity to carry out subsequent construction. In addition, companies also have some problems in material selection. If the quality of the raw materials itself is not high, even if the technology used in the civil engineering construction is very advanced, the desired effect cannot be achieved, and the engineering cost may be increased. Second, the durability of civil construction technology is insufficient. Civil engineering requires long-term use, so the durability requirements are very high. If the construction technology lacks durability, it will affect the long-term development of the entire construction project. Judging from the current development of civil construction technology, the durability of construction technology is seriously insufficient and does not meet the design requirements and engineering standards. In the subsequent construction of the project, it may also increase the probability of common quality defects such as fractures and cracks, and increase the quality and safety risks of the entire construction project. Besides, during the construction of civil engineering, construction personnel did not pay enough attention to durability management, and there may be problems such as rework, extension of construction period, and additional engineering costs, which is not conducive to the overall development of the construction project. Hence, the construction unit must pay attention to the safety and durability of civil construction. Only in this way can the project be completed successfully and the use effect of the project can be improved.

\section{Several Common Technologies and Key Points of Construction in Civil Engineering}

\subsection{Reinforcement Engineering Construction Technology}

The technical characteristics of steel reinforcement engineering are as follows. First, we must ensure the quality of the steel bars when processing the steel bars, select appropriate and high-quality raw materials, and then carry out processing and production in strict accordance with the design requirements. When cutting the material, we need to leave a suitable lap length, mark the position of the bending point of the steel bar and the position of the scribed part [2]. Second, we must check whether the steel bars meet the requirements of civil construction standards when tying the steel bars, including the inspection of the specifications, size, quality and appearance of the steel bars. Then, we should strictly follow the construction sequence to complete the reinforcement binding, and reserve accurate holes. Otherwise, the joints must be staggered, and then the rebar lap joints must be placed accurately. We need to place the main force-bearing steel bars at the bottom and the secondary-bearing steel bars at the top to improve the stability of the steel bar structure.

\subsection{Formwork Construction Technology}

The construction technology of formwork engineering includes fixed formwork construction, column formwork construction and beam formwork and floor formwork construction. Among them, the key points of the top-level formwork construction technology are as follows. First of all, we must place the spacers reasonably and place them in the supporting steel pipes in the roof formwork to prevent the steel from being displaced. Secondly, we should rationally arrange the construction sequence of steel reinforced pipes to ensure that the steel bars are firmly connected and that the upper and lower layers of the steel bars are the same. What'smore, we should also reasonably control the tightness of the formwork. The height of the supporting structure must be adjusted reasonably. When placing the surrounding formwork, it should be flush with the wall and seal measures should be taken to avoid slurry leakage. When constructing the column formwork, first of all, we need to control the accuracy of the elastic line and set the elastic line width according to the standard to ensure the convenience of detection and construction. Besides, we should strictly control the vertical variation range of the column formwork to ensure that the column 
formwork has a higher strength to avoid deformation problems during construction. The beam formwork construction requires that the beam bottom formwork and the side formwork are tightly assembled. Two cushions should be placed on the beam bottom formwork, and longitudinal compression should be placed on the side formwork. Protective facilities should be provided for large-volume beam slabs. The key to the construction of the floor formwork is to ensure the strength of the floor, select high-quality raw materials, and control the height of the bracket to meet the requirements of the construction standard. The function of the above-mentioned formwork is to make preparations for concrete construction, and the concrete pouring sequence is determined according to the direction of the formwork during concrete pouring. These forms can only be removed after the concrete has been poured and hardened to a certain strength.

Table 1: Standards for Template Installation

\begin{tabular}{|l|l|l|}
\hline Serial Number & \multicolumn{1}{|c|}{ Construction Link Name } & Technical Standard \\
\hline 1 & Splicing between two templates & $\leq 1$ \\
\hline 2 & The height difference between two adjacent templates & $\leq 1$ \\
\hline 3 & Flatness of template & $\leq 2$ \\
\hline 4 & Dimensional deviation of the template plane & \pm 3 \\
\hline
\end{tabular}

\subsection{Concrete Engineering Technology \\ Construction}

The construction technology of concrete engineering includes mixing, pouring and vibrating, curing, etc. Among them, the key point of mixing construction technology is to control the configuration ratio of the mixture, select high-quality concrete raw materials, configure according to the design standards and mix them evenly. This requires the relevant staff to control the concrete mixing operation based on on-site construction conditions and transportation conditions, including the proportion of raw materials, the strength and speed of mixing, and the time, especially the amount of water added during mixing [3]. Secondly, check the condition of the steel formwork before pouring the concrete to confirm whether the quality of the material is qualified. When pouring, we should control the number and intensity of vibrating according to the actual situation. According to the different operation methods, the vibrating can be divided into mechanical vibrating and manual vibrating. When the working surface is small or the corners are poured, the manual vibrating method is selected to cooperate with the pouring construction, which can reduce the dependence on mechanical equipment and reduce the construction cost. Generally, we will combine manual vibrating with mechanical vibrating, and choose the insert-type vibrating method to ensure that the concrete fills the gaps during pouring. We must pay attention to the control of the vibrating time and quality. Generally, the vibration should be kept for more than 20s, and the surface leveling can only be continued when there are no bubbles or sinking on the surface of the concrete structure. It must be calibrated once during pouring, and can not continue to vibrate during the initial setting. It can be poured at any time before solidification, and the pouring time is within 6 hours each time. For the pouring construction of larger beams, we should adopt independent pouring to ensure the quality of concrete pouring. Finally, we must pay attention to the maintenance of the finished concrete. For example, sprinkling water to make up for the moisture volatilized when the concrete hardens, avoiding too much water and running water to cause structural cracks or deformation. During the maintenance operation, we need to understand the concrete conditions and reasonably control the temperature and humidity of the concrete structure.

\subsection{Cast-in-place Pile Construction Technology}

Cast-in-place pile construction technology is also one of the commonly used technologies in civil construction. In the construction of cast-in-place piles, we should choose a reasonable method of pile formation based on the actual situation of the specific project, and then clean the site, accurately find the position of the pile hole according to the content of the construction drawings, and carry out the excavation construction under the premise of ensuring the accuracy of the pile hole. For places with high water levels, we should reasonably adopt drainage facilities such as arm guards. We should combine manual excavation and mechanical excavation, and focus on drainage. In order to avoid the problem of pile hole collapse, we should pour and vibrate concrete in time after removing the pile hole water. We need to use mechanical equipment to remove impurities in the holes in time, prepare drainage, trenches and silt ponds and other facilities. We can start the construction of the steel cage after completing the above work, and then carry out the concrete pouring construction and the vibrating construction as required.

\subsection{Brickwork Construction Technology}

The main points of brickwork construction technology in civil construction of building engineering include the following points. Firstly, we need to take targeted measures based on weather conditions before starting brick masonry construction to ensure that the wetness of the bricks meets the requirements of building construction. Secondly, we should do a good job in the corner treatment of the brickwork. Moreover, each coil angle cannot exceed 5 layers, and the large angle shall be lifted, and the line can only be constructed after the coil angle meets the construction requirements. The method of double-sided hanging line is generally adopted during the line hanging construction [4], which can ensure that 
the flatness of the brick body meets the quality requirements. We must ensure that it is fully integrated with the mortar to reduce the occurrence of cracks. Finally, we generally use staggered seams up and down and lay bricks inside and outside to ensure that the brick body is evenly stressed. In order to avoid cracks and instability in the later project.

\section{The Necessity of Innovating Civil Engineering Construction Technology}

\subsection{Social Development Needs}

The progress of science and technology and the development of the market economy have given the construction industry a good opportunity for development. However, from the overall level, there are still some gaps between China's civil engineering construction technology and other developed countries. Analyze the reasons, mainly due to insufficient innovation awareness and imperfect mechanism. For this reason, if we want to better provide advanced technical support for civil engineering construction, we need to continuously strengthen technological innovation. Then, we need to introduce the corresponding construction technology based on the actual project, and do a good job in the construction quality management of the construction project. This will not only speed up the construction progress but also ensure the quality of the project, which will bring more economic and social benefits to the enterprise.

\subsection{The Main Means for Enterprises to Gain Competitive Advantage}

In the fierce competition in the construction market, if an enterprise wants to gain a greater competitive advantage, it must first develop and innovate construction technology and cultivate professional and compound technical personnel. At this stage, most companies have realized the importance of accelerating technological innovation and personnel training. They have combined market changes and their own characteristics in actual development, and they have also formulated many reasonable technological innovation programs and development plans that are compatible with the future development of the company. The competitive system of the construction market also promotes the development of engineering technology to be more practical and innovative, and to apply advanced construction technology to civil engineering construction. This is not only of great significance for improving construction efficiency and quality, but also for enterprises to gain more competitive advantages. Simultaneously, consolidating an enterprise's market position can also reduce its risk and create more economic and social value for it.

\section{Countermeasures and Suggestions for the Innovation and Development of Civil Engineering Construction Technology}

\subsection{Idea Innovation}

First of all, the construction units and construction personnel have changed the traditional construction concepts in the past, and realized the importance of innovative and improved civil construction technology from the ideological perspective. All construction units and construction personnel can through in-depth technical research and the development and application of more new technologies, combined with innovative management methods, ensure the quality of civil construction and reduce engineering costs. Many companies have incorporated the research and application of technological innovation into their development plans, which shows their emphasis on construction technology innovation. We should also actively introduce some appropriate advanced development concepts during the concept innovation, and then optimize the concept content according to the actual situation of the enterprise. This can make it more in line with the needs of the development of the enterprise and serve the construction project.

\subsection{Application Innovation}

The ultimate goal of civil construction technology innovation is to improve the construction quality of construction projects and speed up the progress of construction projects, thereby bringing more economic benefits to construction enterprises. Technology application innovation specifically refers to the continuous improvement of the engineering technology system, the improvement of the applicability of the technology itself, and the improvement of the application value of the technology. In actual application, the active application of advanced technology to the actual construction of the project, and summing up the experience according to the actual construction of the project will help to continuously improve the construction technology system and innovate the construction method. In the meantime, companies also need to strengthen the allocation of various technological innovation resources, including funds, equipment, personnel, materials, and policies, so as to provide support for the application of innovative technologies [5]. Furthermore, after the development of new technologies, we also need to provide a practical environment. According to the practical results, the parameters of the technology application are constantly adjusted, so as to ensure the practical value of the engineering innovation technology. 


\subsection{Mechanism Innovation}

Enterprises should combine the past experience in construction technology application, establish a technology management system, strengthen the innovation and optimization of the internal organizational structure of the enterprise, and make the organization more flexible. Meanwhile, companies should also clarify the work responsibilities of various departments, clarify specific work objectives and work content, so that they can understand industry trends in a timely manner and do a good job in technical external exchanges. Construction technicians must have a firm grasp of industry technical standards and formulate technical management systems in accordance with industry regulations. Actively cooperating with construction personnel to solve technical problems can improve the application value of the system. Mechanism innovation can enable various new technologies, new equipment and new materials to be rationally applied to specific engineering constructions, thereby realizing efficient management and control of construction materials, engineering machinery, and on-site construction safety. We need to implement the responsibilities of various departments and personnel with a comprehensive and complete construction management system, and compile civil construction organization designs based on this. We can organize the construction schedule according to the overall requirements of the project, and implement the deployment and management of various tasks on site and the man-machine environment. So as to lay a good foundation guarantee for the civil construction.

\subsection{Talent Team Building}

If a construction company wants to achieve technological innovation, it must have an independent technological innovation team. Therefore, the company must do a good job in the construction of a technical talent team. In practical applications, enterprises can enrich their technical teams by internally training high-tech talents or introducing innovative talents. Simultaneously, companies should establish corresponding incentive mechanisms to stimulate employees' enthusiasm for work and enable them to actively learn advanced construction methods and construction experience at home and abroad. Afterwards, relevant staff need to combine new materials, new technologies and specific projects to meet the construction and production needs of construction companies.

\section{Conclusion}

In summary, this article analyzes the current development status of civil engineering construction technology. In view of the current civil construction technology still has some safety and durability problems to be solved, we should pay more attention to the innovative application of technology in all aspects of civil construction. We should study how to improve the overall benefits of construction projects by introducing advanced construction technology and equipment and enhancing the operational capabilities of construction personnel is a key issue that needs to be considered in current civil construction. In the future development, only by innovating the construction concept of the enterprise, innovating the technology application mechanism, doing a good job in personnel training, and strengthening the application of new construction technologies and processes, can the supervision of civil construction technology be done well. Only in this way can it bring more economic benefits to the enterprise and promote the overall healthy and sustainable development of the project.

\section{References:}

1. Tian Zhijin. Analysis of optimization measures for construction technology management[J]. Management Observation, 2014, 25: 125-126.

2. Zhang Bo. Research on the construction technology of concrete structures in civil engineering buildings [J]. Building Materials and Decoration, 2015 (48): 103-103.

3. Yan Ruiping. Discussion on construction technology of building engineering and its on-site construction management $[\mathrm{J}]$. Building Engineering Technology and Design, 2015 (11): 1299.

4. Liu Shuicai. Research on civil engineering construction technology at this stage $[\mathrm{J}]$. Engineering Technology Research, 2016 (6): 76.

5. Zhang Shunshun. Analysis of quality control measures for construction technology of building engineering [J]. Housing and Real Estate, 2016 (24): 214. 